\title{
MENAKAR KEKUATAN DAN KEUNGGULAN INDUSTRI TELEVISI LOKAL DI ERA OTONOMI
}

\author{
Gatut Priyowidodo \\ Jurusan Ilmu Komunikasi, Fakultas Ilmu Komunikasi, \\ Universitas Kristen Petra \\ Jalan Siwalankerto 121-131 Surabaya 60236 \\ email:gatpri@ypeter.petra.ac.id
}

\begin{abstract}
The development of industrial television has two sides. In one hand, it gives blessing but on the other hand posses some disadvantages. In autonomy era since 1999, all regional administratives have big opportunities to establish television station. Therefore, they are competing to invite some investors to come. Such as, Bali Post from Bali found Yogya TV, Jawa Pos came to Batam and found Batam TV etc. They are aware that it isn't difficult to manage media firm. TV has more influence than radio or print media. Since 1950, all country in the world had used $T V$ as media to campaign or to socialize their program to people. TV is an effective tool to deliver message to audience. Basicaly, human prefers audio-visual activity than to read or to listen. Through TV, they can take information, entertainment, and also education values. By 2009, there will be more than two hundred television stations established in some cities in Indonesia. Finally, the audiences will have more channels to watch.
\end{abstract}

Keywords: television, industrialization, investor

\section{PENDAHULUAN}

Mesti diakui, jika perkembangan televisi dalam kurun dua dasawarsa belakangan ini luar biasa pesatnya. Tidak saja dilihat dari kuantitas stasiun televisinya, tetapi yang jauh lebih penting adalah pengaruh apa yang ditimbulkan akibat siaran tabung audio visual tersebut. Karakteristik pengaruh sesungguhnya adalah refleksi paling aktual atas jenis atau siaran apa yang diproduksi masing-masing stasiun televisi itu. Itu sebabnya semakin banyak institusi penyiaran baik televisi atau radio mereproduksi siaran yang berdimensi positif, maka harapan akan implikasi pengaruh positif pada khalayak pemirsa dan pendengarnya juga semakin besar. Sebaliknya semakin intens informasi negatif dipancarluaskan masing-masing stasiun tersebut dampak negatifnya pasti juga semakin besar.

Itu sebabnya benar apa yang dikatakan Thorndike (1987) bahwa frekuensi dan intensitas informasi yang kita peroleh akan menentukan apakah perilaku kita akan terpengaruh oleh informasi tersebut. Informasi yang sama, senada atau serupa yang masuk secara berulang-ulang ke dalam diri seseorang akan memberikan pengaruh yang berbeda dengan apabila informasi tersebut hanya diterima sekali. Seringkali tanpa disadari informasi tersebut terinternalisasi ke dalam diri kita dan selanjutnya terealisasikan dalam bentuk perilaku tertentu atau dalam istilah Storey (1993) ia menjadi sebuah 'destructive power'. Bahkan sesuatu informasi yang salah karena berulang-ulang disampaikan tanpa disadari akan dianggap sebagai suatu kebenaran 
Televisi adalah media yang potensial sekali tidak saja untuk menyampaikan informasi tetapi juga membentuk perilaku seseorang, baik ke arah positif maupun negatif, disengaja ataupun tidak. Sebagai media audio visual TV mampu merebut 94 $\%$ saluran masuknya pesan-pesan atau informasi ke dalam jiwa manusia yaitu lewat mata dan telinga. Televisi mampu untuk membuat orang pada umumnya mengingat $50 \%$ dari apa yang mereka lihat dan dengar di layar televisi walaupun hanya sekali ditayangkan. Atau, secara umum orang akan ingat 85\% dari apa yang mereka lihat di TV, setelah 3 jam kemudian dan 65\% setelah 3 hari kemudian. (Dwyer, 1998).

Namun di sisi lain, pada era otonomi daerah, peran media massa makin urgen. Undang-Undang No. 22 Tahun 1999 yang direvisi menjadi Undang-Undang No. 32 Tahun 2004 tentang Pemerintahan Daerah lebih menitikberatkan pada partisipasi dan kontrol masyarakat serta pemberdayaan institusi lokal. Salah satu upaya yang harus dilakukan demi suksesnya otonomi daerah adalah mengoptimalkan peran institusi lokal nonpemerintah, seperti media massa. Konsepsi ideal era otonomi daerah tersebut memberi kesempatan besar bagi media massa lokal untuk lebih berperan aktif, sekaligus merupakan peluang dan tantangan untuk lebih maju daripada media nasional.

Tantangan terberat bagi media lokal tentunya adalah tersedianya kecukupan modal. Sebab industri televisi memang merupakan sektor bisnis yang padat modal (jika dikelola secara profesional). Sebagai gambaran kongkrit, TVRI stasiun lokal misalnya, untuk memproduksi dan menayangkan siaran yang berdurasi hanya satu jam harus mengeluarkan biaya produksi pada kisaran Rp 10-30 juta. Namun jangan takut, Grabak TV yang mengudara di Desa Grabak, Magelang Jawa Tengah, tanpa bermodal kuatpun bisa bersiaran sebanyak tiga kali seminggu yakni Senin, Rabu dan Jumat dengan dana sampiran alias gotong royong.

Boleh jadi untuk sebagian daerah production cost sebesar itu mungkin tidak terlalu besar oleh sebab daerahnya adalah lahan subur untuk iklan. Namun bagaimana dengan daerah yang memang agak kering iklan? Tentu itu persoalan yang pelik tetapi harus tetap bisa disiasati demi survival sebuah institusi penyiaran.

Mekanisme yang jamak ditemukan adalah memperkuat siaran bermuatan lokal. Institusi penyiaran harus mampu mengelola sensitifitas pemirsa melalui peristiwa-peristiwa yang memiliki unsur kedekatan dan menciptakan suasana yang interakstif seolah-olah pemirsa lokal juga menjadi bagian dari siaran yang ditayangkan.

Beberapa stasiun TV lokal seperti JTV (Surabaya) mengemas siaran berita dengan berbahasa Jawa dan Madura. Tentu ini dimaksud untuk merebut pemirsa melalui daya tarik bahasa yang dikuasai mayoritas penontonnya. Bali TV, Yogya TV maupun Borobudur $\mathrm{T}$ sangat jelas mengarahkan siarannya tertuju pada segemen penonton yang terikat oleh kultur lokal. Demikian juga Favorit TV (Padang) misalnya juga menggarap khas siaran adat istiadat minang agar pemirsa tertarik dan iklan yang berskala kecil bisa masuk. Tak mau ketinggalan TV Manado (TVM) maupun TOP (Televisinya Orang Papua) TV juga mencoba mengambil "positioning" dengan kelucuan-kelucuan khas Sulut dan Papua yang jelas tidak mungkin ditemukan dalam siaran televisi nasional.

Contoh-contoh di atas sekedar menggambarkan betapa sesungguhnya jika secara serius muatan lokal itu bisa digarap secara bak dan profesional juga bisa mendatangkan iklan sebagai sumber pendapatan televisi tersebut. 
Kekhasan dan keunikan setiap daerah dimana televisi lokal itu berada semestinya harus dilihat sebagai sebuah potensi sumber pendapatan yang bisa menghidupi lembaga siaran tersebut. Televisi lokal tidak harus sama dengan televisi nasional, sebab cakupan dan materi siaran memang juga tidak sama. Untuk itu ditengah kompetisi perebutan belanja iklan yang sangat ketat setiap stasiun harus jeli dan cermat membaca kecederungan atau tren apa yang bisa dikerjakan secara maksimal.

\section{PEMBAHASAN}

Berdasarkan UU No. 32 Tahun 2002 tentang Penyiaran terbuka kesempatan bagi siapa saja untuk bergerak di bidang industri pertelevisian. Namun tentu tidak dimaksud menjadikan kawasan usaha yang tanpa tapal batas. Rambu-rambu aturan tetap harus dipenuhi mengingat mengelola industri media televisi selain unsur edukasi dan hiburan juga mesti diperhatikan norma-norma kesusilaan atau hal-hal yang bersingungan dengan SARA. (suku, ras, agama dan antar golongan) sebagai issu yang sangat sensitif di Indonesia.

Tentu dengan alasan berbeda-beda, kalangan pemilik modal berusaha untuk terjun dalam industri pertelevisian ini. Namun jika dicermati secara seksama, intinya siapapun mereka yang berusaha untuk menekuni bisnis ini adalah selain mengejar keuntungan ekonomis juga secara ideal berusaha menanamkam pengaruh kepada khalayak pemirsanya. Televisi dianggap piranti modern yang masih sangat ampuh mewujudkan impian tersebut.

Ketika TVRI lahir tahun 1962, tentu bayangannya tidak sekedar untuk mengikuti tren teknologi tapi juga melakukan indoktrinasi ideologi. Terlebih atmosphere politik kala itu sangat sarat sengketa kepentingan ideologis antara kelompok Timur dan Barat. Televisi sebagai barang baru jelas, sekali waktu kelak akan diyakini sebagai piranti ampuh menanamkan pengaruh.

Seiring pergeseran waktu dan kemudian muncul belasan televisi nasional dan puluhan televisi lokal, kekuatan monopoli siaran televisi plat merahpun buyar. Masyarkat bebas memilih siaran domestik apa yang mereka suka. Informasi liar terbang kesana kemari tanpa ada agen kontrol yang mesti ditakuti. KPI/KPID boleh saja berteriak nyaring, tapi seberapa mampu kekuatan mereka melakukan pengawasan siaran yang semakin luas jangkaunnya.

Mengacu pada Pasal 6 buku Standar Program Siaran 2007 KPI yang memuat penghormatan terhadap nilai-nilai agama, norma kesopanan dan kesusilaan, perlindungan anak, remaja dan perempuan, serta pelarangan dan pembatasan adegan seks, kekerasan dan sadisme saja cukup banyak pelanggaran demi pelanggaran terpapar. Itu baru sebagian dari isi satu pasal. Sementara masih ada 78 pasal sisa lainnya yang perlu perhatian lebih cermat.

Sekalipun rawan pelanggaran, televisi sebagai sebuah basis bisnis tetap mengkilap untuk diperebutkan. Itu sebabnya tidak hanya pengusaha nasional, atau asing yang berusaha memasang pertaruhan, namun investor-investor lokalpun banyak yang tergiur memperebutkan berkah tabung bergambar tersebut. Tidak mengherankan hingga tahun 2005 telah berdiri 86 stasiun televisi lokal yang tersebar pada 50 kota besar yang ada di seluruh Indonesia (Gazarin: 2005). 
Tabel 1. Daftar Stasiun Televisi dan Lokasi Perprovinsi di Indonesia

\begin{tabular}{|c|c|c|}
\hline NO. & Lokasi Provinsi & Nama Stasiun \\
\hline 1. & NAD & TVRI Aceh \\
\hline 2. & Sumut & TVRI Medan, Deli TV \\
\hline 3. & Sumbar & TVRI Sumbar, Fa TV, Minang TV, BiTV \\
\hline 4. & Riau & $\begin{array}{l}\text { TVRI Pekan Baru, Riau TV, Riau Channel, GTV, Sam } \\
\text { TV dan SJ TV }\end{array}$ \\
\hline 5. & Kepri & Batam TV, STV \\
\hline 6. & Sumsel & TVRI Sumsel, Palembang TV, Sriwijaya TV \\
\hline 7. & Jambi & TVRI Jambi \\
\hline 8. & Bengkulu & TVRI Bengkulu \\
\hline 9. & Lampung & TVRI Lampung, LTV \\
\hline 10. & Jakarta & $\begin{array}{l}\text { TVRI Jakarta, Elshinta TV, Da Ai TV, JakTV, } \\
\text { O'Channel, Spacetoon }\end{array}$ \\
\hline 11. & Banten & CTV \\
\hline 12. & Jatim & $\begin{array}{l}\text { TVRI Jawa Timur, Agropolitan TV-ATV (Batu), Batu } \\
\text { TV, Dhamma TV (Batu), JTV (Surabaya), GNTV, GTV } \\
\text { (Malang), Logis TV (Kediri), Daha TV (Kediri), } \\
\text { Mahameru TV, Malang TV, Spacetoon (Surabaya), dan } \\
\text { TV Anak (Surabaya), TVE }\end{array}$ \\
\hline 13. & Jabar & $\begin{array}{l}\text { TVRI Bandung, Bandung TV, Bogor TV, CB Channel, } \\
\text { CT Channel, Ganesha TV, Mega Swara TV, MQ TV, } \\
\text { Padjajaran TV, Spacetoon Bandung, SS TV, STV } \\
\end{array}$ \\
\hline 14. & Jateng & $\begin{array}{l}\text { TVRI Semarang, BMS TV, Karesidenan TV, TA TV, TV } \\
\text { Borobudur, TV KU, Pro TV, Cakra TV, TVT, Ratih TV }\end{array}$ \\
\hline 15. & Yogyakarta & TVRI Yogyakarta, Jogya TV, RB TV, Tugu TV \\
\hline 16. & Bali & TVRI Denpasar, Bali TV \\
\hline 17. & NTB & LB TV \\
\hline \begin{tabular}{|l|l|}
18. \\
\end{tabular} & NTT & TVRI Kupang \\
\hline 19. & Kalimantan Selatan & TVRI Banjarmasin, Amuntai TV, Rantau TV \\
\hline 20. & Kalimantan Barat & TVRI Pontianak, KC TV, Ruai TV \\
\hline 21. & Kalimantan Timur & TVRI Samarinda, PK TV, Tarakan TV \\
\hline 22. & Kalimantan Tengah & TVRI Palangkaraya \\
\hline \begin{tabular}{|l|l|}
23. \\
\end{tabular} & Sulawesi Selatan & TVRI Makasar, Makasar TV, Fajar TV, Sinjai TV \\
\hline 24. & Sulawesi Utara & TVRI Manado, Bunaken TV, GO TV, Pacific TV, TVM \\
\hline 25. & Sulawesi Tenggara & Kendari TV \\
\hline 26. & Gorontalo & Gorontalo TV \\
\hline 27. & Maluku & TVRI Ambon \\
\hline 28. & Papua & TVRI Papua, TOP TV \\
\hline
\end{tabular}

Data di atas jelas memberi gambaran faktual, betapa sesungguhnya bisnis pertelevisian amat menjanjikan. Setiap orang pasti membutuhkan hiburan. Dan sarana hiburan paling dekat dengan manusia adalah televisi. Itu sebabnya tidak mengherankan dibanding banyak negara di Asia, rakyat Indonesia jauh paling lama menghabiskan waktunya di depan layar kaca yakni rata-rata 7 jam sehari. Itu 
sebabnya dari perhitungan bisnis, jelas berinvestasi dengan mendirikan stasiun televisi sangat prospek. Bahwa di tengah perjalanan akan berbenturan dengan rumit dan sulitnya mendapatkan iklan sebagai sumber pendapatan, tentu itu perlu trik dagang yang lain lagi.

Mencermati membanjirnya televisi baru itu, muncul pertanyaan apakah televisi-televisi lokal tersebut milik badan hukum yang beragam ataukah justru mengerucut pada segelitir pemilik modal? Ini perlu diperhatikan, mengingat pada level kepemilikan stasiun televisi nasional dari 11 televisi yang ada ternyata sudah mengelompok pada empat kepemilikan. Mereka adalah Group Media Nusantara (MNC), Grup Para, Surya Citra Media (SCM) dan Bakrie. Lalu apakah kondisi yang sama bakal terjadi di televisi lokal? Jumlahnya saja yang banyak namun setelah diruntut, ujung-ujungnya hanya ketemu orang-orang yang kurang lebih sama. Tentang siapa yang pemilik televisi nasional dapat dilihat pada tabel berikut.

\section{Tabel 2. Kepemilikan Televisi Swasta Nasional}

\begin{tabular}{|c|l|l|}
\hline No. & \multicolumn{1}{|c|}{ Nama Grup } & \multicolumn{1}{c|}{ Nama Stasiun Televisi } \\
\hline 1. & Media Nusantara Citra & RCTI, TPI dan Global TV \\
\hline 2. & Para & Trans TV, Trans 7 \\
\hline 3. & Surya Citra Media & SCTV, O Channel, Indosiar (Menyusul) \\
\hline 4. & Bakrie & ANTV, tvOne, JakTV \\
\hline
\end{tabular}

Diluar Metro dan TVRI, nyaris empat grup tersebut mampu menguasai seluruh siaran televisi nasional. Jika empat kelompok besar ini tidak memiliki sparing partner' yang memadai dapat dibayangkan betapa telah terjadi oligopoli sumber informasi. Siapa yang paling dirugikan? Jelas rakyat selaku pemirsa hanya memperoleh sedikit dari obyektifitas berita yang semestinya dipaparkan kepada publik. Terlebih jika media tersebut memiliki agenda terselubung dengan mekanisme pembelian 'blocking time' atau melakukan sinergi atas nama kepentingan tertentu, keberpihakan jelas terjadi.

Televisi lokal, tentu merupakan alternatif selain kabel atau tv berlangganan. Hanya sayangnya untuk pilihan terakhir tersebut masih mesti merogoh sejumlah dana iuran.

Kehadiran televisi lokal yang sekarang sudah menjamur bak cendawan harus disikapi secara bijak. Bahkan berdasarkan pengakuan pengelola media, ada sebuah kelompok media yang sekarang sedang mempersiapkan dan menyiarkan empat ratus stasiun televisi lokal di Indonesia. Jika ini benar, tentu saja tabel di atas akan segera direvisi karena sudah tidak valid lagi.

Perkembangan dari menit ke menit terhadap munculnya berbagai stasiun televisi lokal adalah realitas kesadaran bermedia. Tentu fakta ini mengingatkan pada tahun 1998-2002, seiring dengan lengsernya pak Harto, beragam media cetak lahir tanpa SIUPP atau ijin apapun. Asalkan bisa menerbitkan media cetak (Koran/ majalah), semua orang tidak dihalang-halangi.

Spirit yang sama 10 tahun setelah reformasi kini juga melanda media elektronik. Siapapun bakal diberi kesempatan mendirikan stasiun televisi, asal bisa. Baik persyaratan teknis ataupun administratif, mendirikan televisi sungguh sangat mudah. Jika secara komersial kesulitan, mereka akan menggeser ke televisi komonitas. 
Keinginan manusia agar bisa dilihat sesamanya, sungguh sudah merupakan kebutuhan. Bahwa sebuah televisi semestinya harus menyiarkan acara-acara lengkap yang mencakup, news reporting, talk show, call-in show, documentair, magazine,rural program,advertising, education/instructional, art and culture, music, soap opera/sinetron/drama, TV Movies, game show, comedy dan lain-lain, tangguhkan dulu. Pengelola televisi dengan modal pas-pasan tidak mesti harus mengambil porsi siaran secara keseluruhan. Fokus mereka tentu hanya pada bagaimana siaran tersebut bisa berlangsung dan biaya operasional terjaga. Semangat itulah yang mayoritas melatarbelakangi manajemen produksi siaran televisi lokal.

Melalui perjalanan yang cukup tertatih-tatih beberapa televisi lokal sudah keluar dari ruang ICU dan bahkan sekarang sudah merambah ke pelebaran sayap usaha lainnya. Ini membuktikan bahwa dengan porsi sumber dana iklan yang cekak, tetapi diimbangi dengan armada yang kreatif kesulitan apapun pasti dapat diatasi.

Bahkan seiiring dengan gerakan otonomi daerah berdasarkan UU No 32 Tahun 2004, hampir setiap pemerintah daerah di level kabupaten/kota maupun provinsi sangat membutuhkan sarana sosialisasi hasil-hasil pembangunan. Kepala Daerah tentu sangat berkepentingan kalau hasil sepak terjangnya selama lima tahun diapresiasi dan diketahui publik. Itu sebabnya televisi merupakan sarana yang tepat untuk melakukan sosialisasi dan komunikasi. Kepentingan daerah jelas tidak akan dipenuhi oleh televisi skala nasional. Kalaupun akan menyiarkan, pasti selain space waktu yang singkat juga mesti memuat unsur news yang menjual.

Televisi dalam perjanannya telah mengalami proses metamorfosis fungsi yang luar biasa. Ia tidak saja sebagai media penyampai informasi an sich, namun juga agen perubahan sosio kultural. Bahwa apa yang disampaikan terkadang bias karena kepentingan-kepentingan yang dimainkan tentu itu sudah lama ditengarai. Harold Innis (1894-1952) secara khusus mengkaji tentang bias komunikasi itu. Bahkan televisi juga mengantarkan orang seolah berada dalam suasana desa global seperti disindir Marshall McLuhan (1911-1980). Tak kalah memikatnya, televisi sesungguhnya menurut Herbermas, merupakan 'public shere' atau kawasan discourse dimana gagasan-gagasan dapat dieksplorasi oleh suatu pandangan publik dan perkembangan komunikasi yang jauh melesat menerjang sekat pembatas (Brigg dan Burke, 2006).

Secara matematik, agaknya setiap pemerintah kabupaten/kota dan provinsi memang semestinya memiliki televisi. Di era audio visual seperti saat ini, penggunaan teknologi audio (radio) dan cetak memang sudah kalah pamor. Masyarakat jauh lebih akrab dengan tokoh sinetron ketimbang siapa menteri yang mengurus pertanian atau pekerjaan umum. Tentu semakin menarik jika mensinergikan ketiga media ini dalam rangka akselerasi pembangunan daerah. Jika dimasing-masing kabupaten/kota sudah memiliki radio, tentu tidak demikian dengan televisi.

Dimaklumi, bahwa tidak semua daerah kaya. Itu sebabnya tidak harus setiap kabupaten/kota memaksakan diri mendirikan televisi jika memang keuangan daerah tidak mendukung. Langkah yang strategis adalah melakukan kerjasama tiga-empat kabupaten/kota berdekatan untuk menopang pendirian dan operasionalisasi stasiun televisi tersebut. Ini mungkin yang lebih masuk akal ketimbang secara otonom mendirikan sendiri namun berat bebannya. Kendala lain apakah ruang udara kita cukup tersedia frekwensi bagi setiap stasiun tersebut? 


\section{KESIMPULAN}

Semangat otonomi daerah memang bisa menembus segala penjuru. Bahkan sektor yang dulu tak sempat dipikirkanpun seolah sekarang terbentang lapang di depan mata. Televisi lokal memang tidak sekedar ambisi daerah namun sudah menjadi kebutuhan agar daerah bisa mengkonkritkan. Dulu disetiap kabupaten/kota ada RKPK (Radio Khusus Pemerintah Kabupaten) atau RKPD (Radio Khusus Pemerintah Daerah), mungkinkah dalam lima tahun kedepan juga berdiri televisitelevisi daerah.

Spirit pengelolaan televisi daerah jelas tidak boleh meniru mis manajemen radio daerah. Secara profesional, pemerintah kabupaten/kota ataupun provinsi harus memposisikan televisi daerah tersebut sebagai BUMD yang harus untung namun mengemban visi/misi yang pro rakyat dan pembangunan.

Setiap daerah punya potensi yang luar biasa jika mau dikembangakan. Terhadap pasokan SDM dibidang pertelevisian, tidak usah dikuatirkan. Jurusanjurusan Ilmu Komunikasi yang memiliki program pertelevisian tentu bakal tertarik mengembangkan ilmunya di sana. Daerah tinggal memiliki 'good will' yang jelas, kuat dan terarah agar semua projek besar ini bisa terlaksana.

Bahwa nantinya diperlukan kolaborasi dengan daerah terdekat, itu soal teknis yang mesti mempertaruhkan win-win solution. Prinsip yang perlu dikedepankan adalah daerah sangat berkepentingan atau tidak dengan eksistensi televisi daerah tersebut. Itulah sebabnya sebelum berkeputusan tetap, perlu kajian-kajian yang mendalam dan komprehensif. Pendirian televisi Delta milik Pemkab Sidoarjo Jatim kiranya menjadi pelajaran berharga, agar sebelum semua dilounching ke publik dipastikan dulu bahwa semuanya juga sudah valid dan reliabel.

\section{DAFTAR PUSTAKA}

Briggs, Asa dan Peter Burke. 2006. Sejarah Sosial Media dari Guttenberg sampai Internet, Jakarta: Yayasan Obor Indonesia

Haryanto, Ignatius. 2004. "Kepemilikan Media Terpusat dan Ancaman terhadap Demokrasi” Makalah Seminar Juni

McQuail, Denis. 2002. McQuail's Mass Communication Theory, $4^{\text {th }}$. Edition., London: Sage Publication

Komisi Penyiaran Indonesia. 2007. Standar Program Siaran 2007 Jakarta: KPI

Gardi Gazarin. 2005. "Perkembangan TV Indonesia Meningkat Signifikan" Suara Pembaruan, 26 Desember

Storey, John. 1993. An Introductionary Guide to Culture Theory and Popular Culture Prentice Hall: Hertfordshire

Wijaya, Agung. 2007. "YLKI Kritik Monopoli Bisnis Televisi” Tempo Interaktif 24 Desember 